\title{
A PRODUÇÃO ANALÓGICA DA VERDADE NO PROCESSO PENAL: DESVELANDO A RECONSTRUÇÃO NARRATIVA DOS RASTROS DO PASSADO ${ }^{1}$
}

\author{
Salah H. Khaled Jr. ${ }^{2}$
}

http://dx.doi.org/10.22197/rbdpp.v1i1.9

\begin{abstract}
Resumo
Este artigo pretende discutir o regime da verdade do processo penal, problematizando o conceito de verdade correspondente (real, material, substancial e relativa) a partir de uma epistemologia da passeidade, que procura atentar para a complexidade do tempo escoado que é o referencial cognitivo do processo penal: o conhecimento sobre o passado é construído a partir de rastros, conformando uma verdade analógica que é produzida narrativamente. Com isso, visa o rompimento do paradigma da verdade correspondente utilizada como sustentáculo da busca pela verdade real pelo juiz, resultando o famigerado ativismo judicial, maculando a estrutura acusatória do devido processo legal. A análise pretende superar o isolacionismo do discurso jurídico, atualmente deficitário diante dos novos paradigmas dos discursos dos demais campos do saber.
\end{abstract}

Palavras-chave: Processo Penal. Verdade Correspondente. Ativismo judicial.

\section{ABSTRACT}

This article intends to discuss the regime of the truth on the criminal procedure, questioning the concept of corresponding truth (real, material,

\footnotetext{
1 Esclarecemos que o presente artigo discute de forma sintética o tema de nossa obra $A$ busca da verdade no processo penal: para além da ambição inquisitorial, publicada pela Editora Atlas, remetendo o leitor para uma melhor compreensão das questões aqui tratadas, a partir de um diálogo multidisciplinar com a dogmática processual penal internacional clássica e contemporânea.

2 Professor adjunto de Direito penal, Criminologia, Sistemas Processuais Penais e História das Ideias Jurídicas da Universidade Federal do Rio Grande - FURG. Professor permanente do mestrado em Direito e Justiça Social da Universidade Federal do Rio Grande - FURG. Doutor e mestre em Ciências Criminais (PUCRS). Mestre em História (UFRGS). Especialista em História do Brasil (FAPA). Bacharel em Ciências Jurídicas e Sociais (PUCRS). Licenciado em História (FAPA). Líder do Grupo de Pesquisa Hermenêutica e Ciências Criminais (FURG/CNPq).
} 
substantial and relative) from the passeidade epistemology, which seeks to attempt to the complexity of runoff time which is the cognitive referential of criminal procedure: the knowledge about the past is built from the trail, analog forming one truth that is produced narratively. It face the disruption of the corresponding truth paradigm used as the base for the seek of real truth by the judge, resulting a judicial activism, blemishing the accusatory structure of due process of law. The analyses intend to overcome the isolationism of the legal discourse, currently deficit of the discourse paradigms of the other camps of knowledge.

KEYWORDS: Criminal Procedure. Corresponding Truth. Judicial Activism.

\section{Introdução}

Não há duvida de que ainda há muito a discutir no que diz respeito à questão da verdade no processo penal, principalmente em função dos inúmeros abusos que se tornam possíveis através do recurso ao artifício discursivo da verdade correspondente e à suposta aptidão do juiz para buscar e supostamente encontrar a verdade. Não é por acaso que Ferrajoli afirma que "sem uma adequada teoria da verdade, da verificabilidade e da verificação processual, toda a construção do direito penal do iluminismo [...] termina apoiada na areia; resulta desqualificada, enquanto puramente ideológicas as funções políticas e civis a ela associadas". ${ }^{3}$ Ao discutir a questão, Ferrajoli efetivamente deu um passo além do que tradicionalmente é tido como uma verdade real apreensível pelos meios que o processo disponibiliza, mas infelizmente foi incapaz de romper com o limite discursivo da verdade correspondente. O mesmo pode ser dito de Taruffo, que preso aos parâmetros do racionalismo moderno, também permaneceu vinculado à mesma estrutura de pensamento: um critério de verdade correspondente, ainda que de forma madura e não ingênua, como proposto pelo autor, não basta para promover o urgente e necessário rompimento discursivo. ${ }^{4}$ Em última análise, tanto Ferrajoli quanto Taruffo assumem o modelo de verdade como correspondência, ainda que aproximada e relativa; não rompem com a racionalidade de uma violenta ambição de verdade, apenas a matizam, o que é insuficiente para a concretização de uma estrutura acusatória de contenção regrada do poder punitivo. Em outras palavras, o argumento da verdade correspondente relativa permanece sendo utilizado para sustentar a busca da verdade pelo juiz, conformando um inaceitável ativismo judicial, que rompe com a estrutura acusatória do devido processo legal, autorizando a busca da condenação a qualquer custo.

3 FERRAJOLI, Luigi. Direito e razão: teoria do garantismo penal. São Paulo: RT, 2002. p. 39.

4 TARUFFO, Michelle. Simplemente la verdad: el juez y la construcción de los hechos. Madrid: Marcial Pons, 2010. p. 95. 
O objetivo deste artigo consiste em apresentar as bases iniciais do que chamamos de epistemologia da passeidade. Trata-se de uma epistemologia que procura atentar para a complexidade do real, rompendo com os limites discursivos que caracterizam as epistemologias processuais obcecadas pela busca da verdade. Nesse sentido, é movida por uma intenção de renúncia à característica mais marcante da maquinaria inquisitória: a violência conceitual que renega a complexidade das coisas em nome da persecução desmedida que conforma o critério reitor do sistema. A relação entre o processo penal e os eventos da vida é extremamente complexa: está para além da lógica de resolução da realidade pelo poder cognitivo do sujeito do conhecimento. Os "fatos" não são "evidentes" por si mesmos. O real é resistência: não se curva aos poderes metodológicos do homem racional.

A proposta de trabalho aqui apresentada procura romper com o isolamento do discurso jurídico, inconcebível diante da necessária abertura aos parâmetros discursivos dos demais campos do saber. Como observa Ferrer Beltrán, é habitual enfatizar a especificidade da prova jurídica em relação à prova produzida em qualquer outro âmbito de experiência, argumentando que a atividade probatória está submetida a um grande número de regras jurídicas que fazem dela algo sui generis em relação a atividade probatória em sentido geral; no entanto, essa apreciação é exagerada e pode ser relativizada. ${ }^{5}$ Para o autor, nem a incerteza que caracteriza a tomada de decisão jurídica sobre a prova, nem o caráter regrado da mesma permitem concluir que não é possível aplicar a essa tomada de decisão as categorias e os critérios de racionalidade próprias da epistemologia em geral. ${ }^{6}$ Como destaca Ferrajoli, "no plano semântico, com efeito, a verdade das teses judiciais não difere em princípio da verdade das teorias científicas". ${ }^{7}$ Ferrajoli aponta que os problemas de verificação e verificabilidade, "para as proposições jurídicas fáticas, são mais ou menos os mesmos que se colocam para a verificabilidade e verificação de qualquer proposição histórica. Podem, portanto, beneficiar-se do debate e das reflexões epistemológicas desenvolvidas pela filosofia analítica a propósito desse tipo de proposição". ${ }^{8}$ Taruffo também observou que embora não exista coincidência absoluta entre o juiz e o cientista, isso não significa que não exista uma conexão significativa no que diz respeito ao âmbito da prova e da avaliação dos fatos: as metodologias científicas e os modelos de raciocínio científico podem contribuir para a análise do problema da prova jurídica. ${ }^{9}$ Portanto, a proposta de análise a partir da aproximação com outros campos de saber que será aqui exposta se diferencia de outros estudos que fizeram essa abertura em função dos subsídios incorporados, mas não na intenção de rompimento com o monólogo jurídico, uma vez que Ferrajoli, Taruffo e Ferrer Beltrán já o fizeram,

\footnotetext{
FERRER BELTRÁN, Jordi. La valoración racional de la prueba. Madrid: Marcial Pons, 2007. p. 67.

6 FERRER BELTRÁN, Jordi. La valoración racional de la prueba..., p. 29.

7 FERRAJOLI, Luigi. Direito e razão: teoria do garantismo penal. São Paulo: RT, 2002. p. 42.

8 FERRAJOLI, Luigi. Direito e razão: teoria do garantismo penal..., p. 43. Grifos do autor.

9 TARUFFO, Michele. La prueba de los hechos. Madrid: Trotta, 2005. p. 331.
} 
ainda que a nosso ver, de modo insuficiente. Seguimos a orientação de Gauer, que aponta que "[...] somente por meio de novas linguagens é que se pode fazer a necessária recusa ao saber jurídico sedimentado, isto é, a tudo aquilo que Bachelard designava "obstáculo epistemológico". ${ }^{10}$ Nesse sentido, qual é - usando a expressão de Bachelard - a estética do escondido? ${ }^{11}$

\section{Passeidade e verdade}

A discussão aqui proposta parte do que há de mais característico no núcleo de saber processual e que não deve ser desconsiderado por nenhum método cognitivo: a passeidade do horizonte projetado pelo caso penal, que conduz a um conjunto decididamente denso de perguntas. Enquanto a discussão sobre o método remete ao problema de fundo epistemológico, ou seja, à questão da formação da prova e de seu tratamento no âmbito do processo, a passeidade é a grande questão de fundo ontológico, que não pode continuar a ser ignorada em nome da ambição de verdade. Nesse sentido, é preciso referir que o paradigma moderno oferece fundamentação e legitimação "científica" para práticas processuais que rompem com a estrutura do sistema acusatório, atribuindo ao juiz, enquanto sujeito do conhecimento, a capacidade de extração da essência das coisas. Trata-se de uma concepção de conhecimento que está esgotada e é considerada insuficiente no que se refere aos desafios que envolvem a complexidade do real. Sua adoção enquanto critério de produção da verdade em âmbito processual é desastrosa e apta a produzir enormes danos aos interesses do acusado, pois permite a sobrevivência de uma epistemologia inquisitória no interior de um processo que acaba sendo apenas formalmente acusatório, o que é manifestamente insuficiente para a desejável contenção regrada do poder punitivo.

Partindo dessa perspectiva, a passeidade do evento sobre o qual o juiz forma sua convicção deve ser investigada, pois consiste em um aspecto que é desconsiderado até mesmo por análises mais sofisticadas do que as habituais. É o caso de Ferrer Beltrán, que comparando o juiz e o historiador, diz que não vê muita relevância na aproximação, considerando que o que mais importa para o raciocínio probatório é que se trata de provar fatos individuais irrepetíveis e não de que são fatos passados. ${ }^{12}$ Também é o caso de Taruffo, que ao discutir a aproximação entre o juiz e o historiador, aponta que: "En particular, no se deriva ningún dato relevante de esa analogía en referencia a la noción de prueba y a las modalidades de uso racional de los medios de prueba en el ámbito del proceso." $13 \mathrm{O}$ mais curioso na opinião de Taruffo é que ele efetivamente reconhece que as discussões

10 GAUER, Ruth Maria Chittó. A fundação da norma: para além da racionalidade histórica. Porto Alegre: EDIPUCRS, 2009. p. 113.

11 BACHELARD, Gaston. A poética do espaço. Rio de Janeiro: Eldorado Tijuca, 1960. p. 19.

12 FERRER BELTRÁN, Jordi. La valoración racional de la prueba. Madrid: Marcial Pons, 2007. p. 35.

13 TARUFFO, Michele. La prueba de los hechos. Madrid: Trotta, 2005. p. 341. 
epistemológicas no âmbito da historiografia são muito profundas, mas não as considera relevantes para a discussão da prova no processo. Nesse sentido, ainda que Taruffo e Beltrán tenham prestado valiosas contribuições acadêmicas no campo da prova, permanecem presos aos limites discursivos da cientificidade moderna: creem piamente nos poderes do sujeito do conhecimento, designando ao juiz uma função epistêmica de busca da verdade no processo.

Embora muitos autores desqualifiquem a discussão sobre o esgotamento do parâmetro científico moderno, relacionando a questão aos desdobramentos do que genericamente chamam de "irracionalidade da pós-modernidade", o diagnóstico de insuficiência desse paradigma não é recente. ${ }^{14}$ Como reflete Gauer, "dos finais do XIX aos nossos dias o debate em torno da insuficiência teórica da ciência se constituiu no grande debate,

14 É o caso de Taruffo, que faz uma longa exposição em sua obra "Simplemente la verdad" criticando o que afirma ser embriaguez pós-moderna, que conduziu à ideia de que o conceito de verdade, assim com os de razão, história e conhecimento deveriam ser deixados de lado como instrumentos em que não era possível confiar. No entanto, temos a impressão de que Taruffo comete uma série de equívocos no trecho relacionado, a começar pelo estabelecimento de uma relação de autores tidos como pós-modernos nos quais ele inclui, por exemplo, Heidegger, que sequer pode ser tido como pertencente ao contexto que Taruffo critica. Além disso, suas críticas a Lyotard, Vattimo e Derrida, que são feitas a partir de outras leituras e não das obras originais, revelam uma fundamental incompreensão do que esses autores sustentam (Derrida, Heidegger e Vattimo sequer estão na bibliografia do autor). Ainda que Taruffo considere que o que ele chama de pós-modernidade não foi uma enfermidade do pensamento e que foi provocada uma crise irreversível de algumas ideias ingênuas que não merecem ser retomadas, no final do trecho o autor escamoteia o problema de da verdade, dizendo não ser possível abordar o insolúvel problema de sua definição. Ao final da discussão o autor assume como válido o "critério clássico" proposto por Tarski, para quem o enunciado "a neve é branca" só é verdadeiro se a neve é branca. Com o devido respeito ao autor, essa concepção em nada contribui para fazer avançar a discussão sobre a verdade no processo. TARUFFO, Michele. Simplemente la verdad: el juez e la construcción de los hechos. Madrid: Marcial Pons, 2010. p. 89-98. Diga-se de passagem que Ferrajoli emprega exatamente o mesmo enunciado de Tarski para - em suas palavras - redefinir parcialmente o modelo de verdade como correspondência, motivo pelo qual acreditamos que é preciso ir além dos dois autores. FERRAJOLI, Luigi. Direito e razão: teoria do garantismo penal. São Paulo: RT, 2002. p. 41. Diante das críticas de Taruffo, nos alinhamos com Timm de Souza, que refere que: "A acusação de irracionalidade é uma das retóricas preferidas de modelos de racionalidade hegemônicos para tentar desqualificar outras racionalidades, ou mesmo outras possibilidades da racionalidade. Nada de novo sob o sol: a história da filosofia tem sido, ao longo dos séculos, a tensão entre a promulgação de sistemas e teorias como verdades e a suspeita sempre presente de que a verdade está para além do campo de abrangência de sistemas e teorias." SOUZA, Ricardo Timm de. Razôes Plurais: itinerários da racionalidade ética no século XX: Adorno, Bergson, Derrida, Levinas, Rosenzweig. Porto Alegre: EDIPUCRS, 2004. p. 165. Grifos do autor. Outra objeção que pode ser feita a Taruffo diz respeito ao fato do autor deliberadamente se esquivar de enfrentar temas árduos, ainda que os reconheça como problemas que mereceriam análise. É particularmente o caso das questões que envolvem tempo e causalidade, que não são enfrentadas, mas apenas referidas, indicando que envolvem debates filosóficos e científicos que ele não abordará. Trata-se de uma posição que ele adota em relação a uma série de temas, em vários trechos da obra referida. TARUFFO, Michele. Simplemente la verdad: el juez e la construcción de los hechos. Madrid: Marcial Pons, 2010. p. 68. Além disso, no que se refere à grosseira crítica a uma "pós-modernidade" destacamos a posição de Lyotard, que indica que "[...] nem a modernidade nem a dita pós-modernidade podem ser identificadas e definidas como entidades históricas claramente circunscritas, onde a segunda chegaria sempre depois da primeira". LYOTARD, Jean-François. O inumano. Lisboa: Editorial Estampa, 1997. p. 34. 
principalmente no campo das humanidades". ${ }^{15}$ Dito isso, partimos aqui do postulado de que não é aceitável que um modelo insuficiente até mesmo para as ciências exatas - que já abandonaram, em boa parte, a exatidão em prol da complexidade - permaneça como paradigma dominante no campo jurídico. E isso não é aceitável sob a dúplice ótica da precariedade do conhecimento obtido por esse instrumental e das escassas possibilidades de contenção do poder punitivo que resultam de sua adoção. Com o devido respeito a Taruffo e Beltrán, nosso horizonte compreensivo é incisivamente contrário, considerando que a passeidade é um dos aspectos mais distintivos da verdade produzida - e não encontrada - no processo, motivo pelo qual é a partir desse elemento inicial que uma teoria da verdade processual deve e precisa ser estruturada. Os próprios tempos verbais utilizados tornam clara a referência à passeidade de um tempo escoado. O horizonte projetado pelo caso penal refere-se a uma anterior realidade empírica, ou seja, refere-se a eventos da vida que ocorreram no passado e que são tratados por uma linguagem jurídico-penal que incorpora a eles seu peculiar significado, o que contribui para aprofundar ainda mais a distância entre o evento e sua reconfiguração narrativa. A verdade correspondente está para além das forças dos homens, motivo pelo qual a possibilidade de produção de danos é imensa, já que as eventuais condenações jamais poderão ser tidas como expressão inequívoca de uma verdade correspondente ao passado.

Reconhecemos que essa argumentação é ousada, pois parece conduzir ao raciocínio contrário, ou seja, de que não há relação alguma entre a sentença narrativamente elaborada pelo juiz e a verdade. Não é o que propomos. Nossa posição está para além da dicotomia entre uma verdade absoluta (a chamada verdade real, material, substancial etc.) e a desconsideração completa da verdade (relativismo ou ceticismo radical), sem tampouco alinhar-se com o falso compromisso entre ambas que é a verdade aproximativa ou relativa, que permanece presa ao ideal de correspondência e, logo, apta a fundamentar poderes de ordem inquisitória. É por isso que sustentamos que é necessário romper com o modelo de verdade correspondente para ir além da ambição de verdade no processo penal, o que não significa, no entanto, cair no relativismo cético. Nossa posição nesse sentido assemelha-se a de Rui Cunha Martins. Para o autor, a posição mais fecunda é a que vai para além do clássico paradigma da verdade como adequação resistindo, porém, a fazer dessa ultrapassagem uma porta aberta para o que chama de paradigma da verdade exilada, isto é, expulsa do sistema. ${ }^{16}$ É a partir dessa orientação que a noção de passeidade opera como o postulado a partir do qual deve ser (re)definida a verdade, que não será expulsa, mas redimensionada, perdendo seu lugar canônico no sistema processual penal contemporâneo.

Não escondemos nossa posição em relação ao problema em questão: partimos do postulado de que no processo é produzida uma reconstrução narrativa de um evento

15 GAUER, Ruth Maria Chittó. A ilusão totalizadora e a violência da fragmentação. In: GAUER, Ruth Maria Chittó (Coord.) Sistema penal e violência. Rio de Janeiro: Lumen Juris, 2006. p. 13.

16 CUNHA MARTINS, Rui. O ponto cego do direito: the brazilian lessons. Rio de Janeiro: Lumen Juris, 2010. p. 87. 
que pertence a um tempo escoado, e não uma reprodução equivalente ou aproximativa daquilo que foi, com caráter de verdade correspondente, o que é simplesmente impossível: a incerteza processual não tem como ser abolida por completo, uma vez que o passado não se curva diante dos mecanismos de cognição disponíveis aos homens. No entanto, para condenar - já que para absolver a verdade não entra em questão - o juiz terá que elaborar narrativamente um texto amparado em provas que foram estabelecidas ao longo do processo, momento no qual a verdade irá se mostrar como uma exigência: a exigência de representar o passado.

É preciso dizer antes de tudo que o evento sobre o qual o juiz deve decidir pertence a um tempo que já passou, que não volta mais e que não tem como ser reproduzido de forma alguma. Essa noção é fundamental, pois em grande medida inviabiliza a pretensão de obtenção de uma verdade correspondente pelo sujeito do conhecimento: o passado está para além dos meios de apreensão da cientificidade moderna, que concebe a verdade com o sentido de correspondência. Afinal, não é possível realizar uma experiência que reproduza em circunstâncias controladas o que se deseja conhecer. A ideia de que o processo possa corresponder ao ideal clássico de experimentação científica é insensata, como percebeu Ferrajoli, que atentou para a passeidade. ${ }^{17}$ Para ele, essa constatação "[...] fende profundamente o modelo ideal da verdade processual fática como correspondência objetiva”. ${ }^{18}$ Logo, "a verdade 'certa', 'objetiva' ou 'absoluta' representa sempre a 'expressão de um ideal' inalcançável [...] a ideia contrária de que se pode conseguir e asseverar uma verdade objetiva ou absolutamente certa é, na realidade, uma ingenuidade epistemológica [...]". ${ }^{19}$ A conclusão que o autor extrai dessa linha de raciocínio o levou a afirmar que a verdade deve ser concebida sob o signo de uma verdade correspondente, mas relativa ou aproximativa, o que fez com que ele rejeitasse a verdade absoluta e a aptidão do juiz para buscar a verdade. É nesse sentido que Ferrajoli adverte que o termo verdade não deve ser empregado com implicações metafísicas no sentido de correspondência absoluta. ${ }^{20} \mathrm{O}$ autor avança, mas a nosso ver, ainda de forma insuficiente, pois permanece sustentando a possibilidade de uma verdade correspondente relativa ou aproximativa. ${ }^{21}$ Se por um lado estamos de acordo com a rejeição da verdade absoluta, por outro lado consideramos que a admissão de um regime de verdade estruturado em torno da verdade correspondente sob a forma relativa permanece passível de deslocamento discursivo e, logo, capaz de sustentar o lugar canônico da

17 Para Ferrajoli: "O que o juiz experimenta não são os fatos delituosos objeto do juízo, mas suas provas. De modo não diverso do historiador, não pode, pois, examinar o fato que tem a tarefa de julgar e que escapa, em todo caso, à observação direta, mas somente suas provas, que são experiências de fatos presentes, mesmo se interpretáveis como sinais de fatos passados." FERRAJOLI, Luigi. Direito e razão: teoria do garantismo penal. São Paulo: RT, 2002. p. 44.

18 FERRAJOLI, Luigi. Direito e razão: teoria do garantismo penal. São Paulo: RT, 2002. p. 44.

19 FERRAJOLI, Luigi. Direito e razão: teoria do garantismo penal..., p. 42.

20 FERRAJOLI, Luigi. Direito e razão: teoria do garantismo penal..., p. 41.

21 FERRAJOLI, Luigi. Direito e razão: teoria do garantismo penal..., p. 42, 54, 56 e 435. 
busca da verdade no processo, mesmo que Ferrajoli não o admita. Portanto é preciso romper com essa linha de raciocínio, uma vez que estamos convencidos de que ela acaba perpetuando - inadvertidamente ou não - a continuidade da tradição inquisitória. ${ }^{22}$ Como dissemos, não é que o ponto de partida do raciocínio que diz respeito à impossibilidade de experimentação esteja incorreto; o problema está em não conduzi-lo à ruptura completa com o ideal de verdade correspondente sob qualquer modalidade que venha a assumir. Para levar adiante a questão, é preciso considerar que uma vez que a observação direta não é possível, só resta valer-se de alguma espécie de substitutivo, o que não significa que o conhecimento produzido com base no referencial substitutivo não será pertinente, mas sim que terá que ser situado em outro patamar cognitivo, que não é o da verdade correspondente.

Carnelutti compara a reconstrução do passado no processo com a do historiador, "con esto de peor: el delito es um trozo de camino, del qual quien lo ha recorrido trata de destruir las huellas". ${ }^{23}$ Dessa forma, Carnelutti se pergunta "como hace quien, habiendo caminado a través de los campos, quiere recorrer en sentido contrario el mismo camino? Sigue lãs huellas de su passo". ${ }^{24}$ Com essas considerações de Carnelutti - que em alguma medida sinalizam o que propomos - podemos encaminhar nossa noção de rastro, que é essencial para a estruturação de uma epistemologia processual que considere a questão da passeidade e com isso possibilite a superação do signo da verdade correspondente e da herança inquisitória.

\section{Os rastros do passado}

Pode ser dito com segurança que a questão epistemológica- que envolve o método e a validade da prova, da norma - encobria (ainda encobre) a questão ontológica, entendida como as possibilidades de reefetuação de um tempo escoado em busca de verdades, através de rastros. A necessidade de comprovação para que ocorra uma condenação exige o emprego da prova, enquanto meio apto a produzir o convencimento do juiz, que será posteriormente exteriorizado através da sentença. Como indica Lopes Jr., "através essencialmente - das provas, o processo pretende criar condições para que o juiz exerça sua atividade recognitiva, a partir da qual se produzirá o convencimento externado na

22 Como reflete Cunha Martins: "Enquanto o debate se mantiver dentro das mesmas regras do jogo que outrora conduziram à consagração do "verdadeiro" como eixo central do sistema processual, enquanto a argumentação utilizada para propor o deslocamento funcional partir da mesma província de significado que a argumentação utilizada para re-dizer a centralidade, a possibilidade de produzir uma efectiva reconsideração do problema será sempre escassa." CUNHA MARTINS, Rui. O ponto cego do direito: the brazilian lessons. Rio de Janeiro: Lumen Juris, 2010. p.81.

23 CARNELUTTI, Francesco. Las miserias del proceso penal. México: Cajica, 1965. p. 72.

24 CARNELUTTI, Francesco. Las miserias del proceso penal..., p. 73. 
sentença". ${ }^{25}$ Segundo Coutinho, "o meio de fazer com que a verdade aporte no processo é a prova, forma ou conjunto de elementos através dos quais se constitui a convicção do juiz no caso concreto, em que pese saberem todos não ser só ela a verdadeira formadora do juízo". ${ }^{26}$ Sem abordar aqui a subjetividade que Coutinho está provocativamente referindo, podemos dizer que a referência à prova submete o processo e a convicção do juiz ao que um dia foi: não é aceitável uma decisão condenatória sem que um substrato probatório consistente esteja presente nos autos. Mas como se dá o convencimento do juiz através da atividade probatória, se o acesso direto não é possível, pois o "fato" não é experimentável? Parece haver aqui uma barreira ontológica insuperável entre presente e passado, entre o que é e o que foi. O que rompe ou ao menos permite em alguma medida a comunicabilidade entre os dois lados dessa barreira é o rastro, uma noção a que dedicamos fundamental importância e que agora passaremos a explorar.

Os rastros são a matéria-prima das provas processuais: o processo não consiste em um debate desprovido de referência concreta ao passado; não é (ou não deve ser) uma mera estrutura formal de enfrentamento entre partes que objetivam a vitória, nem tampouco um jogo que possa ter o resultado determinado arbitrariamente pelo juiz. $\mathrm{O}$ rastro conforma um meio através do qual um evento da vida que pertence a um tempo já escoado pode ser em alguma medida conhecido. Mas o que significa propriamente um rastro e por que a noção aqui proposta reconhece a passeidade do passado, o que não pode ser dito do conhecimento estruturado nas premissas da verdade correspondente, seja ela absoluta (ou real) ou relativa?

Em primeiro lugar, devemos destacar que o rastro se refere ao passado, sendo algo que, no entanto, é presente. Isto não é exatamente uma novidade: Heidegger percebeu uma curiosa duplicidade de sentido. Segundo ele, "o passado pertence, indiscutivelmente, ao tempo anterior, aos acontecimentos de então. Mas pode, não obstante, ainda ser simplesmente dado 'hoje', como por exemplo, as ruínas de um templo grego. Com ele, um 'pedaço do passado' ainda está 'presente'”. ${ }^{27}$ Parece claro que essa noção absolutamente desafia o estatuto ontológico do passado histórico como um simples "já foi". Para Heidegger, o "mundo" a que esses restos pertenceram não existe mais; mas por outro lado, o caráter intramundano desse mundo ainda é dado, como utensílio que subsiste agora, que apesar de sua passeidade, permanece pertinente. Ou seja, os rastros se situam em uma curiosa tensão de pertencimento e não pertencimento ao passado que se deseja conhecer: evocam simultaneamente signos de presença e de ausência, o que conforma uma paradoxo que deveria causar perplexidade, como observou Ricoeur. ${ }^{28} \mathrm{O}$

25 LOPES JR, Aury. Direito processual penal e sua conformidade constitucional. Rio de Janeiro: Lumen Juris, 2010. p. 500. Grifos do autor.

26 COUTINHO, Jacinto Nelson de Miranda. Glosas ao verdade, dúvida e certeza, de Francesco Carnelutti, para os operadores do Direito. In: Anuário Ibero-americano de direitos humanos. Rio de Janeiro: Lumen Juris, 2002. p. 177.

27 HEIDEGGER, Martin. Ser e tempo. Petrópolis: Vozes, 2005. Parte II. p. 183.

28 RICOEUR, Paul. Tempo e narrativa. Campinas, SP: Papyrus, 1997, tomo III. p. 129. Grifos do autor. 
rastro é, ao mesmo tempo, um resto e um signo do que foi e não é mais. ${ }^{29}$ Ele evoca uma ausência - o evento que pertence a um tempo escoado -, sendo simultaneamente, uma presença: significa sem fazer aparecer. ${ }^{30}$ Não é o passado, mas é uma marca do passado que sobrevive, que persiste, que remete ao passado, já extinto pela flecha do tempo. É através de rastros que se busca alcançar o que foi mas já não é. ${ }^{31}$ Eis um paradoxo: um passado desaparecido que, no entanto, foi - foi "real". ${ }^{32} \mathrm{O}$ rastro apresenta uma curiosa duplicidade de sentido, pois indica a dinâmica da passagem e a estática da marca que ficou, que se fixou. ${ }^{33}$ De certa forma o rastro é um traço do passado que permite que ele de alguma maneira se sustente, que permaneça existindo no presente, o que viabiliza - com as devidas ressalvas - o conhecimento sobre o passado. Portanto, há um nexo de dependência em relação à preservação do rastro, que é insuperável, pois ele é a via remanescente. Ele é o que restou do que foi. Sem ele, não é possível reconstituir um percurso. ${ }^{34}$ Ricoeur define tais rastros como conectores em relação ao passado, pois é através deles que uma realidade já extinta pela passagem do tempo pode ser "acessada". ${ }^{35}$ Nesse sentido, o rastro também é uma coisa, uma marca. ${ }^{36}$ Ele combina o vestígio de uma passagem e a relação de causalidade que se inclui na coisidade da marca, que por excelência, suscita perguntas. Ou seja, o rastro é um efeito-signo, cujo referencial sempre será indireto.

É importante observar-se a noção de referência indireta, pois ela é de grande valia para o entendimento de que o conhecimento sobre o passado não pode ser situado na esfera da verdade correspondente. Um conhecimento construído a partir de rastros como é o caso da dimensão de saber processual - é necessária e obrigatoriamente, um conhecimento que embora pertinente, pertence a outro patamar cognitivo que o da correspondência. O tempo intuído a partir do rastro não é o tempo que passou, mas outro... Um tempo representado narrativamente, mas não trazido de volta. É um tempo elaborado - ou melhor dizendo, produzido - a partir do rastro. Produzido somente a partir de rastros, em relação de perfeita ou relativa adequação? Certamente que não. É um tempo elaborado a partir de um lugar de fala, que não escapa da historicidade e do pertencimento a uma tradição e de pré-juizos, motivo pelo qual a verdade terá que ser tida como produzida narrativamente por um juiz que é "ser no mundo" e que tenta apreender um grande todo, que sempre se mostrará inapreensível.

29 RICOEUR, Paul. Tempo e narrativa, tomo III..., p. 10.

30 Ricoeur reconhece sua dupla dívida para com Heidegger e Levinas na definição do rastro. Ver RICOEUR, Paul. Tempo e narrativa. Campinas, SP: Papyrus, 1997, tomo III. p. 179-209.

31 RICOEUR, Paul. Tempo e narrativa. Campinas, SP: Papyrus, 1997. tomo III. p. 11.

32 RICOEUR, Paul. Tempo e narrativa. Campinas, SP: Papyrus, 1997. tomo III. p. 175.

33 RICOEUR, Paul. Tempo e narrativa, tomo III..., p. 200. Grifos do autor.

34 RICOEUR, Paul. Tempo e narrativa, tomo III..., p. 201.

35 RICOEUR, Paul. Tempo e narrativa, tomo III..., p. 174.

36 RICOEUR, Paul. Tempo e narrativa, tomo III..., p. 202. 


\section{O mesmo, o outro e o análogo: representância e representação narrativa do passado}

O que pode representar a noção de rastro para o insustentável conceito de verdade correspondente? O conceito remete diretamente ao que Ricoeur define como o signo do Mesmo, ou seja, a vontade ou percepção de reefetuação do passado no presente. ${ }^{37}$ Todavia, o passado não pode ser um Mesmo em relação ao presente, mas sim, se aproxima de um Outro, que não volta mais e não pode ser reefetuado de forma alguma. O que é proposto com a verdade correspondente é uma ontologia presenteísta que se sobrepõe ao passado e ao que resta dele, o rastro. Em suma, o que se propõe nesta perspectiva é a anulação da distância temporal, uma completa impossibilidade. O presente, não pode ser o ponto culminante de referência da verdade, a não ser que conscientemente ocorra uma opção pela verdade violenta e tautológica de um processo penal do inimigo; ele deve manter-se aberto às possibilidades que os rastros podem indicar, mas não efetivamente corresponder. Quando se afirma que é obtida a verdade correspondente no processo, simplesmente é abolida a diferença em relação ao passado, em função do apriorismo do presente. Por isso essa é uma verdade violenta: além de não reconhecer, anula, mata a diferença que é o signo distintivo do passado. Tal concepção de verdade supõe que é possível abolir tanto a opacidade do passado, quanto a própria opacidade da consciência, que se tornaria transparente a si mesma de forma a evitar qualquer possível contaminação (confirmação persecutória de hipóteses prévias), autorizando a busca da verdade irrestritamente; ou alternativamente, que a opacidade do passado e a contaminação da consciência interfeririam de forma mínima, permitindo a adoção de um critério de verdade correspondente aproximativa, o que também autoriza que o juiz parta em busca dessa correspondência, ainda que com certos limites para evitar a produção de danos.

O equívoco fundamental dessa posição é que o rastro jamais pode corresponder ao passado em si: é apenas indício dele, pois exprime simultaneamente presença e ausência, como Heidegger percebeu. O rastro, com efeito, na medida em que é deixado pelo passado, vale como se fosse ele: exerce uma função de substituição, sobre a qual sempre irá pairar uma nuvem de incerteza, que permanece mesmo após ter sido superada a condição precária de elemento que dá suporte a uma tese e atestada a qualidade de rastro do passado. Ele é apenas parte de um grande todo ao qual ele não pode corresponder; dizer que há essa correspondência é um manifesto excesso

\footnotetext{
37 Ricoeur coloca que: "A primeira maneira de pensar a passeidade do passado é subtrair-lhe o aguilhão, ou seja, a distância temporal. A operação histórica aparece então, como uma des-distanciação, uma identificação com o que outrora foi. Essa concepção não deixa de ter apoio na prática historiadora. O rastro, enquanto tal, não é ele próprio presente? Remontar o rastro não é tornar os acontecimentos passados a que ele conduz contemporâneos de seu próprio rastro? Leitores de história, não somos nós mesmos transformados em contemporâneos dos acontecimentos passados através de uma reconstrução viva de seu encadeamento? Em suma, é o passado inteligível a não ser como persistindo no presente?" RICOEUR, Paul. Tempo e narrativa. Campinas, SP: Papyrus, 1997, tomo III. p. 180-244.
} 
epistêmico. Mas por outro lado, a relação de outridade do tempo escoado não esgota completamente a questão, pois há uma presença, através da concretude do rastro e de quem o interpreta. Aqui está o enigma, o paradoxo fundamental que o conhecimento sobre passado representa: ele aparentemente desafia qualquer categorização, consistindo, por excelência, em uma aporia.

Se por um lado, o passado não pode ser um Mesmo, por outro lado também não pode ser um Outro, pura e simplesmente, caso esteja preservado na forma de rastros. Somente considerá-lo em função da distância acaba produzindo uma ontologia negadora do passado, uma vez que mesmo tendo sido, ele persiste na forma de rastros e, portanto, de certa forma, ainda é. O conhecimento que se sustenta em provas não é Outro completo em relação ao tempo que escoou, desprovido de qualquer relação significativa com o que ocorreu no passado. O conhecimento sobre o passado não pode ter o estatuto de uma verdade correspondente (no sentido de o Mesmo), mas também não é completamente Outro em relação ao passado (o que implicaria falsidade pela diferença absoluta e reduziria o processo a mero jogo argumentativo marcado pelo decisionismo).

O caminho da desconsideração completa da verdade quanto ao passado certamente não é o caminho a seguir, pois a simples ênfase na distância subtrai um ingrediente de complexidade do problema: a diferença entre outrem de hoje e de outrora, que reside na passeidade e no caráter ontológico peculiar de permanência do rastro. Há uma dificuldade específica ligada à sobrevivência do passado no presente que não pode ser subtraída, pois é ela que diferencia o conhecimento do outro do conhecimento do passado. A alteridade do passado não pode predominar completamente sobre a permanência do passado no presente, através dos rastros. Afinal, é a confirmação do caráter de rastro de um elemento apresentado pelas partes que possibilita as provas em sentido processual, algo do qual não se pode abrir mão: os rastros têm um peso próprio que lhes é inerente e não podem ser pura e simplesmente deslocados em função da vontade das partes ou do próprio juiz. Os rastros podem não dizer tudo a respeito do passado a que se referem, mas por outro lado, eles têm poder de veto. Ou seja, eles exercem função proibitiva, pois estabelecem um limite: não é possível sustentar argumentos e a validade de certas conclusões sem recorrer a eles ou então, os contrariando diretamente; o juiz não pode condenar sem narrativamente fazer jus à exigência de verdade na sentença, pois terá que referir elementos que através da atividade probatória em contraditório foram elevados à condição de provas: rastros que em alguma medida permitem rastrear tentativamente o passado. Não basta que ele tenha formado sua convicção sobre a condenação: terá que indicar os motivos probatórios que o levaram a formá-la, ainda que os rastros não tenham o condão de preencher completamente o déficit de veracidade que sempre atingirá essa produção narrativa, o que parece enfatizar o regime do Outro.

No entanto, a possibilidade de reivindicação de uma sustentação empírica para os argumentos suscitados faz com que não seja possível desligar por completo o processo da verdade; como vimos, há uma presença através do rastro, que significa um resto do passado sobre o qual é possível construir uma argumentação que visa obter a captura psíquica do juiz, ou seja, mostrar-se como verdadeira. Essa referência faz do conhe- 
cimento com base nos rastros algo que se sustenta em um fundo de verdade - ainda que insuficiente para lhe atribuir isoladamente o signo do Mesmo -, o que o diferencia de qualquer outro âmbito que não tenha esse rigor referencial, como a literatura, por exemplo. No entanto, a reivindicação desse referencial não basta para superar a outridade do passado, residindo nesse ponto a aporia a ser enfrentada para propriamente começar a definir o regime de verdade adequado para o processo. Presença e ausência; Mesmo e Outro; é na resolução desse enigma que reside a chave para a compreensão do estatuto de verdade adequado à passeidade.

Como referimos anteriormente, nossa intenção ao procurar definir o regime de verdade do processo penal tem como horizonte de sentido a proposta de Rui Cunha Martins, que considera que uma estratégia de expulsão do verdadeiro acabaria por tornar-se contraproducente. No entanto, nossa intenção aparentemente nos conduziu a um paradoxo que deve ser ao menos parcialmente solucionado para que possamos prosseguir, o que não significa que iremos sucumbir à tentação de assumir a verdade correspondente sob a forma relativa como regime de verdade do processo. Nesse aspecto reside um ponto crucial: os autores que assumem a perspectiva da correspondência relativa avançam em relação aos autores que defendem a verdade absoluta (real, material, substancial etc.) na medida em que não negam por completo a outridade do passado. Desse modo, diante do paradoxo com que se deparam, acabam encontrando uma espécie de compromisso entre o signo do Mesmo e do Outro ao assumir a variante relativa ou aproximativa da verdade correspondente, que no entanto, permanece remetendo ao signo do Mesmo e atribuindo ao sujeito do conhecimento a capacidade de buscar a verdade. A saída que propomos para este imbróglio será fundamentalmente distinta, pois como insistimos, não admitimos a verdade correspondente sequer sob a forma relativa. Nesse sentido, qual é o regime de verdade apropriado para o processo penal, que pode fazer com que ele evite o excesso epistêmico das verdades correspondentes - o que vale também para suas versões aproximativas - e os perigos inerentes ao relativismo que desconsidera por completo a verdade?

Ricoeur oferece um possível sentido singelo a essa pergunta, referindo-se a "uma expressão comum ao pintor e ao historiador: ambos procuram 'restituir' uma paisagem, um curso de acontecimentos. O autor reflete que "sob esse termo 'restituir', reconheço o desígnio de 'devolver o que é seu' ao que é e ao que foi”. ${ }^{38}$ Certamente que o juiz que elabora uma sentença condenatória também o faz munido dessa intenção: ao motivar a condenação ele produz uma representação narrativa que acredita ser fiel, correspondendo ao tempo escoado sobre o qual tomou uma decisão, com base em rastros do passado. Afinal, para ele ficou provada a culpabilidade do acusado. Se não tivesse ficado provada, temos que supor que ele simplesmente não condenaria.

É justamente nesse aspecto que introduzimos uma grande inquietude, ao estabelecer que os rastros não permitem essa relação correspondente, demonstrando a insu-

38 RICOEUR, Paul. Tempo e narrativa. Campinas: Papyrus, 1997, tomo III. p. 256. 
primível incerteza que caracteriza o regime de verdade processual. Mesmo a condenação aparentemente mais inequívoca e, logo, que mais parece se aproximar do ideal de correspondência será incapaz de satisfazê-lo. Como inicialmente ilustramos, o ideal de verdade correspondente não é adequado para a representação narrativa produzida no processo, por inúmeros motivos. Qual poderia então, ser a solução para a aporia do regime de verdade da representação narrativa do passado, que permita romper com a ilusão da busca da verdade correspondente e dessa forma estruturar uma epistemologia da passeidade conducente a funcionar como dique contra a torrente do poder punitivo? ${ }^{39}$

Ricoeur buscou aprofundar a discussão sobre a natureza do conhecimento produzido sobre o passado, indo além do conceito de representação, o que fez com que elaborasse a noção de representância. Ele considera que "[...] o passado é o 'face-a-face' a que o conhecimento histórico se esforça por corresponder de maneira apropriada, através do rastro". ${ }^{40}$ Entretanto, há uma diferença significativa entre a ideia de que há uma tentativa de correspondência quando o juiz elabora a sentença condenatória e considerar-se que a correspondência pode ser atingida. É claro que se ao escrever o juiz faz uma construção - pois produz algo narrativamente -, ele gostaria que essa construção fosse uma reconstrução o mais equivalente possível ao que um dia foi; ou seja, que ele está condenando porque realmente o acusado é culpado e, logo, que foi atingida a verdade correspondente.É exatamente aí que reside o nó górdio da questão: no esforço por corresponder ao tempo escoado e na assunção de que essa correspondência é possível, o que motivará as variantes da verdade correspondente ou da verdade correspondente sob a forma relativa ou aproximativa; no entanto, já vimos que o ideal de correspondência está para além do que o rastro ontologicamente possibilita: permanece irresolúvel a aporia.

É aqui que a filosofia de Ricoeur nos permitirá ultrapassar a tentação de considerar que a dinâmica do Mesmo e do Outro conduz a um modelo de verdade correspondente relativa ou aproximativa. Para Ricoeur, a tentativa de correspondência em relação a um tempo escoado está ligada a um sentimento de representância, de uma dívida para com o passado, que é, em essência, impagável, dada a impossibilidade de sua quitação. Nesse sentido, o termo representância indica as relações entre as construções narrativas da história e o seu face-a-face, a saber, um passado ao mesmo tempo abolido e preservado em seus rastros. Segundo Ricoeur a representância implica uma dívida para com o passado, da qual o historiador é perpetuamente insolvente. ${ }^{41}$ Para ele, a representância é a maneira menos má de render homenagem ao único enfoque reconstrutivo disponível a serviço da verdade em história, no qual é reconhecida sua insuficiência constitutiva em relação ao tempo escoado que se deseja representar. ${ }^{42}$

39 ZAFFARONI, Eugenio Raul; BATISTA, Nilo; ALAGIA, Alejandro; SLOKAR, Alejandro. Direito penal Brasileiro - I. Rio de Janeiro: Revan, 2003. p. 156-157.

40 RICOEUR, Paul. Tempo e narrativa. Campinas: Papyrus, 1997, tomo III. p. 242. Grifos do autor.

41 RICOEUR, Paul. Tempo e narrativa. Campinas: Papyrus, 1997, tomo III. p. 175.

42 RICOEUR, Paul. La memória, la historia, el olvido. Madrid: Editorial Trotta, 2003. p. 376. 
Portanto, a verdade correspondente é um excesso epistêmico inaceitável. O conhecimento sobre o passado absolutamente não pode sustentar-se sob o signo do Mesmo. A verdade que o juiz narrativamente produz trata-se de algo ontologicamente distinto do passado que ele deseja representar, motivo pelo qual restará somente representância: assim como o historiador, o juiz será inevitavelmente um devedor insolvente em relação ao passado. De fato, a passeidade do passado é uma diferença inalcançável e insuprimível. Os meios de acesso que nos restam - através de meros rastros do passado, cuja função é de substituição e não de correspondência - não superam a complexidade de um objeto que resiste à aproximação. Trata-se de uma resistência que não tem como ser vencida através de nenhuma epistemologia processual. Não há como superar esse distanciamento, pois o obstáculo imposto pela passeidade é de uma resistência que é ontológica em si mesma: o passado foi e não é mais; não há como subtrair-lhe o que tem de mais característico, ou seja, sua passeidade. Mas mesmo assim... mesmo assim, de alguma forma, apesar desse tempo que se foi, o evento passado permanece, se mantém através do rastro, o que também impede que o conhecimento sobre o passado não tenha pertinência nenhuma, sendo absolutamente Outro em relação a ele: novamente surge a tentação de fazer a opção pela verdade correspondente relativa.

No entanto, trata-se de uma tentação a qual se deve resistir, pois não só ela não expressa de forma adequada a particularidade da passeidade do passado, como se mostra conducente aos abusos da busca da verdade. Podemos dizer que é em torno de um equívoco fundamental quanto às possibilidades do rastro que se sustentam três posições inaceitáveis no que diz respeito ao regime de verdade do processo, uma vez que todas são aptas a produzir enormes danos ao acusado. As duas primeiras admitem a verdade correspondente, ainda que de formas ligeiramente distintas, enquanto a terceira recusa a verdade por completo: (a) a ideia de que a verdade absoluta pode ser atingida e que deve ser perseguida a qualquer custo; (b) a aspiração à verdade correspondente (que ainda é mantida ao reconhecer-se a aptidão para o juiz buscar a verdade, ainda que a atinja somente de forma relativa). Finalmente, (c) a posição que rejeita por completo a verdade ao afirmar que o passado é só distância, que não tem como ser acessado de forma alguma, conformando um relativismo cético radical. Curiosamente, são três posicionamentos que acabam conduzindo ao mesmo resultado inaceitável: maximizam os espaços potestativos de decisionismo processual, pois apostam no poder do juiz, assassinando contraditório. As duas primeiras posições sustentam a verdade correspondente ao passado, pretensão que conduz ao protagonismo do juiz e, logo, permite o decisionismo. A terceira posição, por sua vez, também maximiza os espaços de decisionismo, ao rejeitar toda validade à noção de prova: potencialmente qualquer coisa vale.

A chave para a resolução do enigma está na própria noção de rastro, que necessariamente conduz à representância de Ricoeur. É a partir da noção de rastro que sustentamos que o conhecimento sobre o passado não deve ser situado isoladamente no âmbito do Mesmo, ou do Outro. Caso esteja embasada em rastros do passado, a narrativa elaborada pelo juiz deve ser situada em uma terceira esfera ontológica: a do Análogo. Por Análogo, compreenda-se simultaneamente, Ser-como e Não- 
-ser; uma verdade que opera no âmbito da constante tensão entre o desvelamento e o encobrimento (cenário de guerra processual), para finalmente ser analogicamente produzida na forma narrativa pelo juiz - que necessariamente agregará algo seu, mesmo com uma postura receptiva - já que é ser-no-mundo. Portanto, trata-se de uma verdade enquanto (re)produção analógica do passado e não enquanto correspondência - ainda que relativa ou aproximada - em relação a um evento que pertence a um tempo escoado. É nesse sentido, em oposição ao excesso epistêmico do conceito de verdade correspondente, que Ricoeur, livremente inspirado no "Sofista" de Platão, pensou nos seguintes gêneros: o Mesmo, o Outro e o Análogo. Segundo Ricoeur, a relação com "[...] a realidade do passado deve passar sucessivamente pelo crivo do Mesmo, do Outro e do Análogo". ${ }^{43}$ Portanto, o rastro pode fazer papel de Mesmo (porque é um vestígio do passado, que no momento é presente) ainda que o passado seja um Outro (do qual o acesso através dos rastros será sempre limitado, porque é apenas parte de um todo que já foi e, logo, deve ser reconhecida a alteridade do passado). A partir da tensão entre o crivo sucessivo do Mesmo e do Outro, surgem provas, que podem embasar a elaboração narrativa do Análogo, ou seja, Ser-como e Não-ser, o que não expressa de modo algum um modelo de verdade como correspondência. ${ }^{44}$ Afinal, é isto que um artefato narrativo que tentativamente rastreia o passado de forma substitutiva pode evocar: "as coisas devem ter se passado como se diz nessa narrativa; graças ao crivo tropológico, o Ser-como do acontecimento passado é levado à linguagem". ${ }^{45}$

O grande equívoco está em considerar o signo do Mesmo (verdade correspondente) e do Outro (afastamento completo da verdade) de forma isolada, ou apenas relativizando o Mesmo em função da distância do Outro; como vimos anteriormente, Heidegger percebeu que o rastro expressa simultaneamente presença e ausência, o que exige um regime absolutamente distinto de verdade, que como dissemos, passa pelo crivo do Mesmo, do Outro e, finalmente, do Análogo: Ser-como e Não-ser, o que não expressa uma verdade correspondente, mas por outro lado, não expulsa a verdade por completo do processo; apenas a reposiciona de forma a eliminar a patologia de seu caráter canônico, pois é uma concepção dada a inspirar cuidados, em oposição à noção de correspondência, que resulta na assunção de onipotência. A atividade probatória terá que ser concebida de acordo com essa complexidade, o que está para além da estrutura binária de verdade/não-verdade e de sua matização sob a forma da verdade relativa, que continua a permitir inúmeros abusos através na crença nos poderes do sujeito do conhecimento para buscar a verdade.

Ao aprofundar a perspectiva de análise que remete o fundo cognitivo do processo à dimensão de passeidade, percebe-se que chegamos a conclusões mais ousadas do que

43 RICOEUR, Paul. Tempo e narrativa. Campinas, SP: Papyrus, 1997, tomo III. p. 258.

44 Que não se incorra em equívoco. Não há nenhum relativismo exacerbado aqui. O peso da provas garante à narrativa histórica e judiciária a sua especificidade referencial. Como diz Ricoeur: "Dito isso, admito de bom grado que, isolado do contexto dos dois outros gêneros - o Mesmo e o Outro - e sobretudo isolado da pressão que exerce sobre o discurso o face-a-face - o Gegenüber - em que consiste o ter-sido do acontecimento passado, o recurso à tropologia ameaça apagar a fronteira entre ficção e a história." RICOEUR, Paul. Tempo e narrativa. Campinas, SP: Papyrus, 1997, tomo III. p. 259. Grifos do autor.

45 RICOEUR, Paul. Tempo e narrativa. Campinas, SP: Papyrus, 1997, tomo III. p. 258. Grifos do autor. 
as de Ferrajoli, que fez uma aproximação entre o juiz e o historiador, mas não remeteu sua resolução ao fundo ontológico explorado por Ricoeur. Se já acreditamos ter dado um passo além de Ferrajoli em virtude de rompermos com a verdade correspondente sob a forma relativa, nosso distanciamento em relação à Taruffo - e por extensão Beltran - é ainda mais significativo e agudo, pois chegamos a conclusões radicalmente opostas ao modelo estruturado em torno da razão moderna que eles defendem. Nesse sentido, já observamos que em relação a estes autores nossa divergência não se restringe à questão da verdade correspondente relativa - como em Ferrajoli - mas centra-se fundamentalmente na crença nos poderes do juiz - enquanto sujeito racional - para buscar ativamente a verdade correspondente no processo (corretamente rejeitada por Ferrajoli). É sob este aspecto que a investigação acerca da passeidade - e o consequente descortinar dos signos do Mesmo, do Outro e do Análogo - nos permite sustentar que o caráter analógico da verdade narrativamente produzida no processo penal deve conduzir à ênfase nas regras do jogo e, logo, à separação das funções de acusar e julgar e à gestão da prova nas mãos das partes. Seo decisionismo toma conta e o juiz imita a liberdade de criação divina, as chances de condenação equivocada são gigantescas, como discutimos em outra oportunidade. ${ }^{46}$

As considerações aqui elencadas conduzem ao reconhecimento de que não se trata de uma simples adequação ao passado, com caráter de verdade correspondente: 0 artefato narrativo que toma o lugar do evento passado para efeito da decisão somente pode fazê-lo analogicamente. É inaceitável um regime de verdade processual baseado no signo do Mesmo: o rastro é apenas indicativo; ele é o que restou, um pedaço do passado que remanesce, o que permite produzir um conhecimento narrativo de caráter Análogo, isto é, Ser-como e Não-ser. Diante disso, como aponta Carnelutti, o risco está em errar o caminho, devido à falibilidade das provas; e o dano é grave, especialmente quando o passado é reconstruído para determinar o destino de um homem. ${ }^{47} \mathrm{O}$ próprio Taruffo reconhece essa dificuldade, ao apontar que os perigos de erros, lacunas, manipulações e reconstruções incorretas dos fatos são particularmente frequentes e sérios, podendo levar a erros substanciais e equívocos dramáticos na decisão final de uma controvérsia. ${ }^{48} \mathrm{O}$ fato é que se tomada em seu rigor absoluto, uma epistemologia da passeidade conduziria à impossibilidade de qualquer condenação, diante da insuprimível insuficiência de uma narrativa decisória de ordem analógica que toma como base os rastros, cuja função é de substituição - de lugar-tenência - e não de correspondência ao que já foi. Diante disso, é claro que não podemos deixar de esboçar uma pertinente provocação: se a natureza da instrumentalidade processual deve ser dada pelo direito material em que ela se funda, a consideração de que o regime de verdade do processo penal é estruturado em torno do signo do Análogo nos leva a

46 KHALED JR., Salah H. A busca da verdade no processo penal: para além da ambição inquisitorial. São Paulo: Atlas, 2013.

47 CARNELUTTI, Francesco. Las miserias del proceso penal. México: Cajica, 1965. p. 73.

48 TARUFFO, Michele. Simplemente la verdad: el juez e la construcción de los hechos. Madrid: Marcial Pons, 2010. p. 49. 
conclusões interessantes, uma vez que o direito penal veda a analogia, a não ser in bonam partem. É claro que não estamos deslegitimando por completo a jurisdição penal, pois isso significaria por em questão toda a estrutura do sistema e acreditamos que essa estrutura tem virtudes para a contenção do poder punitivo que permanecem irrealizadas, devido à patológica ambição de verdade ${ }^{49}$ Portanto, não estamos dizendo que todas as condenações são equivocadas, mas que a produção narrativa da verdade sob o signo do análogo sempre se dará sob grande tensão e incerteza e será na melhor das hipóteses, contingencial, mesmo que as regras do devido processo legal sejam integralmente seguidas. ${ }^{50}$ Concordando com Lopes Jr., "a verdade assim é contingencial e a legitimação da decisão se dá - somente pode se dar - através da estrita observância das regras do devido processo". ${ }^{51}$ Dizer que a verdade é contingencial significa abrir mão desse fim - a busca da verdade - e assumir outro horizonte, em que juiz deverá estar predisposto a absolver, por exigência da presunção de inocência: em outras palavras, o valor inocência deve ser estruturante do processo penal, inclusive no que se refere à função do juiz, rompendo com a epistemologia inquisitória orientada à persecução do inimigo.

\section{Considerações finais}

Ao descortinar os signos do Mesmo, do Outro e do Análogo demonstramos o imenso risco de produção de danos que é inerente ao sistema e, logo, a necessidade de romper com o discurso da busca da verdade, pois ele maximiza a chance de que tais danos venham a ocorrer. Logo, precisamos de controles mais rigorosos, para enfatizar as regras do jogo em detrimento de qualquer potencial ambição de verdade e com isso procurar superar uma epistemologia que é a expressão de uma violência contra o acusado e a realidade. Uma epistemologia da passeidade evidencia que a jurisdição penal somente pode se legitimar como estrutura de contenção do poder punitivo dedicada primordialmente à redução de danos, o que é absolutamente incompatível com a perspectiva de busca da verdade pelo juiz. Desse modo, a partir do devido desenvolvimento do contraditório, ele pode - e apenas pode - produzir uma verdade que analogicamente expresse a função de lugar-tenência em relação ao passado e que certamente não será uma simples mentira, possibilitando a condenação. No entanto, inevitavelmente a própria impossibilidade de obtenção de uma verdade correspondente - não

49 Em alguma medida Ferrajoli se aproximou desse raciocínio ao esboçar a seguinte reflexão: "A rigor se se pensasse que o juízo penal devesse alcançar a verdade "objetiva" e se tomasse ao pé da letra o princípio do in dubio pro reo, as margens irredutíveis de incerteza, que caracterizam a verdade processual, deveriam comportar a ilegitimidade de qualquer condenação e, portanto, a paralisia da função judicial". FERRAJOLI, Luigi. Direito e razão: teoria do garantismo penal. São Paulo: RT, 2002. p. 51.

50 Acreditamos ter sido suficientemente enfáticos quando dissemos que o regime do Outro não expressa as condições de possibilidade do conhecimento sobre o passado. Como observa Lopes Jr, do mesmo modo que seria grosseiro dizer que a sentença é pura e simplesmente uma mentira, seria grosseira e errônea a crítica à nossa posição neste sentido. LOPES JR., Aury. Direito processual penal e sua conformidade constitucional. Rio de Janeiro: Lumen Juris, 2010. p. 541.

51 LOPES JR., Aury. Direito processual penal e sua conformidade constitucional. Rio de Janeiro: Lumen Juris, 2010. p. 541. 
importando qual a epistemologia adotada - sempre fará com que exista uma irredutível margem de ilegitimidade em toda condenação, o que deve conduzir a um urgente reforço do dique de contenção do poder punitivo, conforme as regras do jogo, procurando reduzir os danos decorrentes de condenações equivocadas, típicas de um processo penal movido pela ambição de verdade.

\section{Referências Bibliográficas}

BACHELARD, Gaston. A poética do espaço. Rio de Janeiro: Eldorado Tijuca, 1960.

CARNELUTTI, Francesco. Las miserias del proceso penal. México: Cajica, 1965.

COUTINHO, Jacinto Nelson de Miranda. Glosas ao verdade, dúvida e certeza, de Francesco Carnelutti, para os operadores do Direito. In: Anuário Ibero-americano de direitos humanos. Rio de Janeiro: Lumen Juris, 2002.

CUNHA MARTINS, Rui. O ponto cego do direito: the brazilian lessons. Rio de Janeiro: Lumen Juris, 2010.

FERRAJOLI, Luigi. Direito e razão: teoria do garantismo penal. São Paulo: RT, 2002.

FERRER BELTRÁN, Jordi. La valoración racional de la prueba. Madrid: Marcial Pons, 2007.

GAUER, Ruth Maria Chittó. A fundação da norma: para além da racionalidade histórica. Porto Alegre: EDIPUCRS, 2009.

. A ilusão totalizadora e a violência da fragmentação. In: GAUER, Ruth Maria Chittó (coord.) Sistema penal e violência. Rio de Janeiro: Lumen Juris, 2006.

HEIDEGGER, Martin. Ser e Tempo. Petrópolis: Vozes, 2005. Parte II.

KHALED JR., Salah H. A busca da verdade no processo penal: para além da ambição inquisitorial. São Paulo: Atlas, 2013.

LOPES JR, Aury. Direito processual penal e sua conformidade constitucional. Rio de Janeiro: Lumen Juris, 2010.

LYOTARD, Jean-François. O inumano. Lisboa: Editorial Estampa, 1997.

RICOEUR, Paul. La memória, la historia, el olvido. Madrid: Editorial Trotta, 2003.

. Tempo e narrativa. Campinas: Papyrus, 1997. Tomo III.

SOUZA, Ricardo Timm de. Razões Plurais: itinerários da racionalidade ética no século XX: Adorno, Bergson, Derrida, Levinas, Rosenzweig. Porto Alegre: EDIPUCRS, 2004.

TARUFFO, Michele. La prueba de los hechos. Madrid: Trotta, 2005.

Pons, 2010.

Simplemente la verdad: el juez y la construcción de los hechos. Madrid: Marcial

ZAFFARONI, Eugenio Raul; BATISTA, Nilo; ALAGIA, Alejandro; SLOKAR, Alejandro. Direito penal brasileiro - I. Rio de Janeiro: Revan, 2003. 